\title{
Employee Satisfaction in Sport: Development of a Multi-Dimensional Model in Coaching
}

\author{
Marlene A. Dixon and Stacy Warner \\ The University of Texas at Austin
}

\begin{abstract}
Despite the overwhelming emphasis on job satisfaction in sport management research, scholars continue to advocate for the distinctiveness and importance of evaluating both job satisfaction and dissatisfaction. The purpose of this investigation is to develop a model of job satisfaction and dissatisfaction for intercollegiate coaches. Fifteen head coaches participated in semistructured interviews. Results revealed a sport industry specific three-factor model. Desirable job factors (Player-Coach Relationships, Recognition, and Social Status) were related only to satisfaction. Industry Standard Factors (Sport Policy, Salary, Recruiting, Supervision, and Life Balance) were related only to dissatisfaction. Performance Dependent Factors (Flexibility and Control, Program Building, and Relationships with Colleagues) were related to satisfaction and dissatisfaction. The results support the distinctiveness of job satisfaction and dissatisfaction as constructs, and also demonstrate a continued need for examining job attitudes within context. As sport managers understand the particular expectations of their employees and their industry they can better diagnose and solve employee issues.
\end{abstract}

While job satisfaction is an important variable in its own right, and is probably the most studied variable in organizational research (Spector, 1997), scholars continue to focus on its relationship to behavioral outcomes such as turnover and performance (Judge, Thoresen, Bono, \& Patton, 2001; Li, 1993; Ostroff, 1992). For example, job satisfaction has been shown to have a negative relationship to turnover (Chelladurai \& Ogasawara, 2003; Currivan, 2000). There is also consistent evidence that satisfaction is positively related to performance (Judge et al., 2001; Steel \& Rentsch, 1997). Therefore, the exploration of satisfaction is important not only for assessing attitudes toward work, but also as part of a larger picture of job performance of both the individual and the organization. As such, it remains a critical avenue for investigation in human resource management.

A number of scholars, however, have argued that satisfaction only reveals part of the paradigm regarding job attitudes and outcomes, and that exploration of dissatisfaction is also necessary to gain a full understanding of such outcomes (e.g., Berger et al., 1993; Kano, 1984; Herzberg, Mausner, \& Snyderman, 1959;

Dixon and Warner are with the Dept. of Kinesiology and Health Education, The University of Texas at Austin, Austin, TX 78712. 
Herzberg, 1966; Matzler, Fuchs, \& Schubert, 2004). These scholars have argued that satisfaction and dissatisfaction are in fact distinct constructs rather than opposite ends of a continuum. As such, the relationship between various factors and the satisfaction or dissatisfaction experienced is not necessarily linear (Berger et al., 1993). For example, Herzberg and colleagues (1959) argued that factors such as job challenge were related to satisfaction, but not dissatisfaction, while other factors like supervision were related to dissatisfaction, but not satisfaction. Similarly, Kano (1984) argued that some product features were related to consumer satisfaction, some to dissatisfaction, some to both, and some to neither. These scholars argued that knowing which factors were related to which outcome could help managers diagnose problems and motivate consumers or employees more effectively. That is, not all job elements should be treated equally, and measures that only include job satisfaction are somewhat limited in their ability to help explain, predict, and influence employees (Berger et al., 1993; Matzler et al., 2004). Building a model that would include both satisfaction and dissatisfaction would contribute considerably to our understanding of employee behavior within organizations.

Further, Kellett (1999) argued that, as the field of sport management evolves, we need to develop domain-specific theory, then use that theory to "inform the nonsport literatures from which we initially draw" (p. 151). Her argument followed Edwards (1999) who suggested a greater need for developing theory based on the real lives of practicing sport managers and Chalip $(1990,1997,2006)$ who argued for the value in sport management research of utilizing narrative approaches and action research that involve those being studied, rather than imposing only strict "expert-derived" approaches in our inquiries. The value of this type of research is not only in enhancing its quality, but also in aiding its appropriate interpretation and application to management policies and practice (Chalip, 1997).

Given the need for better understanding the role of attitudes and behaviors in coaching and for developing sport-specific theory, the purpose of this investigation is to describe and develop a model of job satisfaction and dissatisfaction for intercollegiate coaches. By understanding both facets, and by grounding them in their context, we can continue to develop comprehensive theory of individual and organizational effectiveness, including motivation, performance, and turnover that inform not only sport management, but other literatures as well. In taking a more grounded approach, we need not and should not assume a "naive or atheoretical stance" nor do we "mandate ignorance of relevant scholarship in an area" (Sandelowski, 1993, p. 213), but instead we open ourselves to new theoretical relationships and boundaries that are contextually based (Charmaz, 1990; Geertz, 1973). Thus, before seeking to extend theory, it is appropriate to examine existing literature on both the social and cultural contexts of coaching as well as employee motivation and job satisfaction.

\section{The Coaching Context}

Subcultures may be defined as segments of a society embracing certain distinctive cultural elements of their own. These elements include a shared set of identifiable beliefs, values, and means of symbolic expression (Geertz, 1973; Green, 2001). As coaches enter into the profession, they look to these values, beliefs, and behaviors as a way of establishing their expectations for the profession. Similar to any pro- 
fession, their job satisfaction is then based on these expectations and whether their current position and its specific job features are meeting (or not) their expectations (Berger et al., 1993; Herzberg et al., 1959; Matzler et al., 2004). Therefore, it is important to understand the elements of a coaching subculture that may be essential to establishing the norms of that profession, particularly those that may be unique to the profession (Chalip, 1978).

The current sport literature offers some insight into the subculture of coaching and the norms and expectations thereof. These subcultural elements include, but are not limited to the following: long, nontraditional work schedules, year-round responsibilities, athlete development, and a culture of sacrifice.

First, a number of authors have emphasized that coaching is a nontraditional profession in terms of working hours and time commitment (Chalip, 1978; Dixon \& Bruening, 2007; Sagas \& Cunningham, 2005; Theberge, 1992). Dixon and Bruening (2007) described coaching in the following manner:

The multi-faceted, high paced work setting full of practices, recruiting, offseason workouts, administrative duties and teaching responsibilities has created an environment where only those willing to work twelve hours days, six days a week, for fifty weeks a year can thrive. (p. 384)

Coaching jobs require long, nontraditional hours, and extensive travel. Coaches work to provide evening and weekend games and events that serve as entertainment for other members of their communities. Therefore, work often interferes directly with the coaches' own leisure time and potentially family activities as well (Chalip, 1978; Dixon \& Bruening, 2007; Staines \& Pleck, 1984). While coaches understand and expect these working conditions, some coaches have reported that they accept these conditions in large part because they are given flexibility with when and where they complete their work on the whole (Dixon \& Bruening, 2007). Thus, there may be expectations in coaching not only regarding long hours, but also regarding flexibility within those hours.

Further, the current climate of the coaching profession is that it is a year-round vocation (Brown \& Little, 2001). The extensive work hours exist not only during the playing season, but for many coaches (especially at the college level) even into the months following the final game when the recruiting of new prospects is an essential component of the job (Coakley, 1986; Dixon \& Bruening, 2007). Such hours continue with off-season workouts, meetings, and summer sport camps in the weeks leading up to the beginning of the season. Coaches come to expect that their "busy season" extends well-beyond the playing season itself (Brown \& Little, 2001; Dixon \& Bruening, 2007). This type of work establishes a subculture that the coach will be a "toiler." Doherty (1985) viewed a toiler as "one who engages in fatiguing, emotionally stressful, and ever arduous work for long hours day after day" (p. 11). Therefore, coaches expect a climate of hard work and they usually demand such effort from their staff and athletes as well.

Besides putting together a winning team, coaches have other responsibilities that require time and energy. Coaches are many times a salesperson, as they sell themselves, the program, and the institution not only to future players and their families, but to the community that surrounds their program. One of a coach's primary responsibilities is to help athletes develop as people (Chalip, 1978; Martens, 2004; Weiss \& Stevens, 1993). Often coaches serve as a parental figure as 
they have a primary concern for the players (Doherty, 1985). The parental role is essential especially among college athletes as they are often away from their homes for the first time. Therefore, some coaches seem to see a large part of their job as human development, not simply creation of a performance product (Chalip, 1978; Martens, 2004; Weiss \& Stevens, 1993). The centrality of the human development component, however, likely fluctuates based on level of competition, with more emphasis at lower levels and less emphasis at more elite levels (cf. Chalip, 1978).

As coaches operate in multiple roles with varying emphasis on each role according to coaching context, it is sometimes difficult to measure achievement and success. Is it measured by wins and losses? By an athlete or team improvement? By athletes' citizenship? By the number and quality of recruits? By the level of athlete enjoyment and retention? Difficulty in defining success and agreeing upon that definition between various stakeholders can be a source of frustration and conflict for coaches (Chalip, 1978; Cunningham \& Dixon, 2003) and may be an important facet impacting a coach's job attitudes.

Finally, Hughes and Coakley (1991) suggested that being an athlete or coach involves making sacrifices for the game. The coach is expected to love the game above all else, and prove it by subordinating other interests for the sake of an exclusive commitment to the game that would encompass doing whatever is necessary to meet the demands of a team or competition. Sport nurtures the concept of sacrifice for success, where athletes and coaches are praised for sacrificing all other aspects of their lives in pursuit of achieving their athletic goals (Dixon et al., 2006; Sage, 1998). There is an implicit expectation that the hard work and sacrifice will pay off in terms of personal and/or team success, which leads to ego gratification for the coach (Chalip, 1978). However, such sacrifice may lead to pressure and strain within the coaching role, which may end in burnout and withdrawal (Inglis, Danylchuk, \& Pastore, 2000; Theberge, 1992; Weiss \& Stevens, 1993).

It is within the coaching subculture and against this backdrop of expectations that coaches perform their jobs and live their lives. Understanding the nuances of this subculture, the current study seeks to extend more general theory on job satisfaction by placing it in the specific context of coaches (Geertz, 1973; Kano, 1984).

\section{Coaching Satisfaction}

A number of studies within sport management have investigated the role of satisfaction in the work outcomes of coaches. Dixon and Pastore (2003) explored the role of human resource management practices on coaching satisfaction, commitment, tenure, and performance. They found that coaches were generally very satisfied with their jobs, and human resource sophistication had little impact on job attitude. Pastore (1993), Snyder (1990), and Yusof (1998), however, all found a significant relationship between leadership behaviors of athletic directors and coaches' job satisfaction at various coaching levels. Thus, it seems plausible that management may have some impact on job satisfaction.

In one of the most comprehensive studies, Chelladurai and Ogasawara (2003) investigated the satisfaction of Japanese and American collegiate coaches using their well-developed Coaching Satisfaction Questionnaire (CSQ), which measured 11 equally-weighted dimensions of satisfaction including supervision, coaching job, autonomy, facilities, media and community support, pay, team performance, 
amount of work, colleagues, athletes' academic performance, and job security. They found that the highest levels of reported satisfaction were with intrinsic elements such as the job itself and autonomy. The lowest reported satisfaction was with pay, community and media support, facilities, and supervision. The authors noted the consistency of these findings with Herzberg's two-factor theory (Herzberg, 1966, 1968; Herzberg, Mausner, Peterson, \& Capwell, 1957; Herzberg et al., 1959) that argued that job content was more important to satisfaction than manageriallyfocused variables such as pay or working environment. This finding is also congruent with Raedeke, Warren, and Granzyk's (2002) work with current and former swim coaches, which demonstrated that intrinsic factors such as the enjoyment of working with athletes, the challenge of building a successful program, and feelings of self-satisfaction were the most important coaching benefits. Together, these studies demonstrate the multidimensionality of satisfaction, the relevance of job attitude inquiry in the coaching profession, and the importance of intrinsic job factors in enhancing job satisfaction (which is also related to commitment and turnover (Dixon \& Pastore, 2003; Raedeke et al., 2002).

In spite of much progress, this line of inquiry remains almost exclusively based on instruments that measure only job satisfaction (and not also dissatisfaction). For example, Chelladurai and Ogasawara's (2003) Coaching Satisfaction Questionnaire covered 11 factors related to job satisfaction, but no factors related to job dissatisfaction. Likewise, Raedeke and colleagues (2002), Snyder (1990), and Yusof (1998) all found multiple elements related to satisfaction, but did not distinctly measure dissatisfaction. This is problematic because it essentially assumes that job satisfaction and job dissatisfaction are polar ends of the same continuum rather than distinct constructs. That is, researchers assume that if a job factor does not lead to satisfaction, then it must lead to dissatisfaction, rather than embracing the possibility that various job factors could be related independently to each outcome. Therefore, researchers do not explain how each job factor independently relates to work behaviors and attitudes. If managers can understand the important elements related to both employee satisfaction and dissatisfaction, they can garner more precise direction in managing human resources.

\section{Job Satisfaction and Dissatisfaction}

One of the most significant contributions to the job attitude literature has been Herzberg's dual factor job satisfaction model developed in the 1950s and 1960s. Herzberg's model, called the "Motivation-Hygiene Theory," was developed after extensive interviewing and analysis of the job elements that led employees to feel either especially good or especially bad about their work. From these interviews and analysis, the theory that job satisfaction and job dissatisfaction were not opposites, but rather distinct constructs was developed (e.g., Herzberg, 1966; Herzberg et al., 1959).

\section{Distinction Between Satisfiers and Dissatisfiers}

According to Herzberg, satisfiers (motivators) are those intrinsic factors related to content of the job, and dissatisfiers (hygiene) are extrinsic factors that relate to the context or environment surrounding the job. His model identified achievement, 
recognition for achievement, interesting work, increased responsibility, growth, and advancement as job factors that influenced job satisfaction. Company policy and administration practices, supervision, interpersonal relationships, working conditions, salary, status, and security were classified as hygiene factors, that contributed to job dissatisfaction (Herzberg, 1966; Herzberg et al., 1959).

The major contribution of Herzberg's work was that job satisfaction and dissatisfaction were not opposites, but distinct constructs with identifiable antecedents and consequences. For example, factors such as having interesting work and opportunities for growth impacted job satisfaction, but the absence of these elements did not impact job dissatisfaction. That is, not having interesting work did not necessarily induce employees to detest their jobs, it just did not provide any motivation for them to do their jobs better. Conversely, factors such as working conditions and supervision could lead to dissatisfaction if they were poor, but not to satisfaction if they were great. For example, having an office with a window did not necessarily induce an employee to work harder, but having dark, dismal conditions could lead to a great deal of dissatisfaction.

The dual factor model has received much support in subsequent inquiry. For example, both Chelladurai and Ogasawara (2003) and Raedeke et al. (2002), despite not addressing dissatisfaction in their studies, found general support for this model in coaching investigations. Further, Knoop (1994) found that variables Herzberg labeled as motivators clearly loaded on the intrinsic dimension of job satisfaction and hygiene factors loaded on the extrinsic dimension. More specifically, achievement, recognition, the job itself, and responsibility contributed to the variance in job satisfaction. Although smaller, the extrinsic or hygiene factors explained variance on job dissatisfaction.

Critics of Herzberg's model have argued, however, that it has two main limitations. First, it has been difficult to replicate the results of his study with methodology other than the critical incident approach or technique (e.g., Friedlander, 1964; Hulin \& Smith, 1967). That is, generally when people are asked to recall events, they tend to attribute positive outcomes to their own efforts and abilities, and negative outcomes to other agents (Vroom, 1964). A second limitation is that not all job factors mapped exclusively on satisfaction or dissatisfaction. In fact, $31 \%$ of the factors contributing to job dissatisfaction were motivators and $19 \%$ of the factors contributing to job satisfaction were hygiene factors (Herzberg et al., 1959). Thus, it appears the two factors could be somewhat over generalized and potentially overlook individual and/or industry differences.

With regard to the first limitation, the critical incident technique has been discussed in the management literature and is a widely supported and used qualitative method for eliciting rich descriptive data about significant events in a person's life, especially those that are contextually based (Butterfield, Borgen, Amundson, \& Maglio, 2005; Edvardsson, 1992, 1998; Flanagan, 1954; Stitt-Gohdes, Lambrecht, \& Reddman, 2000; Woolsey, 1986). The technique has been found to be credible, reliable, and valid both for observing behaviors and for participant recall of current and past incidents (Butterfield et al., 2005; Ronan \& Latham, 1974). As Herzberg (1966) argued, "While it is not possible to eliminate bias, conscious or unconscious, on the part of the subjects when using verbal methods (written scales or interviews), at least it is much more difficult to conjure up appropriate events in one's life during a patterned interview than it is to respond 'appropriately' to 
items in a questionnaire" (p. 131). Proponents of the method, therefore, argue that although underlying assumptions must always be checked and data interpreted in light of biases, context, and existing literature, such interpretive caution is typical in the research process and the critical incident approach holds up to tests of reliability, validity, and credibility (see Butterfield et al., 2005 for a review). The critical incident method, therefore is a sound approach for gathering data from the participant's perspective, in his or her own words and interpretation, which aids in the development of contextually based theory such as that of the current study.

\section{Kano's Model of Customer Satisfaction}

Kano's (1984) Customer Satisfaction Model has been instrumental in extending Herzberg's theory and in addressing the limitation of overlapping factors (see also Berger et al., 1993; Martensen \& Gronholdt, 2001; Nilsson-Witell \& Fundin, 2005). Kano developed a four-dimensional model of customer satisfaction, arguing that customers will have different reactions (satisfaction or dissatisfaction) to a product or service based on their expectations of that product or service and whether those expectations were met/fulfilled. Based on customer or employee reaction to various product or service elements, managers could make decisions about how to design, market, and/or package the product or service. Each of the four dimensions is explained below.

First, Kano argued that for some products or services, customer satisfaction level will be proportional to how much it meets customer expectations (or how functional the product is); this dimension is termed "One-dimensional." If the product meets their expectations, customers will be satisfied, if it is not, they will be dissatisfied. This type of job or product element is important because its functionality, or match with employee expectations, is directly proportional to satisfaction and dissatisfaction.

Second, Kano argued that some product aspects will lead to customer dissatisfaction if customer expectations are not met (or the product is not functional), but will not lead to customer satisfaction even if they are fully met. These product aspects are termed "Must-be" and are similar to Herzberg's hygiene factors. An example of a Must-be element would be towels at a workout facility. If no towels were available, customers would likely be dissatisfied, but having towels available would not necessarily lead to high satisfaction. Must-be features are expected to be a standard part of a product or service. These features are important because often designers or managers may focus on enhancing these features assuming that enhancements will lead to customer satisfaction, when in fact these features simply must be maintained to prevent dissatisfaction.

Third, some features will lead to customer satisfaction if they meet expectations (or are functional), but will not lead to dissatisfaction if expectations are not met; this dimension is termed "Attractive" and is similar to Herzberg's motivation factor. For example, if a stadium or arena offered covered parking, customers may be highly satisfied, but if it did not, customers would not necessarily be dissatisfied because they typically expect to park outside. This type of element may be important for distinguishing a product or service, but would not necessarily have to be part of the core service or product features - it can enhance satisfaction, but does not lead to dissatisfaction. 
Finally, some product elements will not lead to satisfaction or dissatisfaction regardless of expectations or functionality; this dimension is termed "Indifferent" and indicates that the customer does not really care if the product element is functional or not. For example, having free coffee available for customers in a ticket-office would probably not impact customer satisfaction one way or another.

\section{The Employee-Grounded Experience}

Kano's model, in summary, focuses on customers' reactions to met or unmet expectations regarding features of a product or service. Although his model was developed primarily to evaluate a customer's response to different product or service features, scholars have demonstrated that Kano's model could also be applied to evaluate an employee's response to different job features or elements (Martensen \& Gronholdt, 2001; Matzler et al., 2004). One may argue, however, that although parallels exist between customer and employee satisfaction (Hallowell, Schlesinger, \& Zornitsky, 1996; Mohr-Jackson, 1991), a customer's interaction with a product or service is usually shorter than that of an employee's interaction with his or her job. This difference in timeframes may call into question the ready applicability of a customer-based model to an employment situation.

In response to this, one strength of Kano's model is that unlike Herzberg's classifications (motivation and hygiene factors) that were static, Kano's classifications are dynamic and adaptive to varying situations and contexts, making it suitable for customers or employees. That is, Herzberg's classifications are determined a priori and the model does not acknowledge or account for individual, situational, or environmental differences (Matzler et al., 2004). For example, in Herzberg's model, salary is always considered a hygiene factor regardless of time, place, industry, position, or economic conditions. In Kano's approach, product or job features are placed into one of the three dimensions after the targeted "voice of the customer" is heard, allowing for individual differences and preferences to emerge and for changes in preferences and expectations to be examined. For example, salary could be a Must-be element in one industry, but an Attractive feature in another. Similarly, over time (or based on particular expectations) a feature could change classifications (e.g., an Attractive element could become a Must-be element). Using a previous example, if most stadia began to offer covered parking, then what was once an Attractive element, could develop into an expected or Must-be element. Therefore, because of its dynamic nature, Kano's model allows for contextual and temporal flexibility, making it applicable to both customer and employment settings.

Building on this theoretical paradigm that argues for satisfaction and dissatisfaction as multidimensional, complex, dynamic, and embedded in employee expectations, the goal of this study is to examine and define the job elements related to satisfaction and dissatisfaction within the college coaching setting, and use this information-rich data to build a foundation for further development of a contextspecific coaching satisfaction model.

\section{Method}

This study utilizes a qualitative approach. By talking with the coaches themselves, we can capture more specific information regarding the conflicts and realities in 
the coaching world, which may be similar or different to other employment settings. A second related reason for the qualitative approach is that the coaches can describe the problem in their own words, not within researcher-imposed constructs (Strauss \& Corbin, 1998). The qualitative approach allows the researcher to "focus on the vagaries of everyday life and on the perspective of those involved ... it confirms the reality experienced by practitioners and demonstrated concretely the connections among research activity, theory, and pragmatic concerns" (LeCompte \& Preissle, 1993, p. 28).

\section{Participants}

Participants were 15 college coaches representing both men's and women's major and minor sports. Specifically, the sample included men's and women's basketball (major sport) and soccer (minor sport) from six NCAA Division III universities in the southwestern United States (see Table 1). These sports were chosen because they are widely represented at Division III schools, both male and female teams are typically found at any given school, and each team usually has its own coaching staff (i.e., unlike tennis, golf, or track and field where both the men's and women's teams may be coached by a single individual). While the schools chosen were geographically convenient, effort was made to select schools with a varying range of admission standards, academic reputations, athletic success, and size of institution and athletic department.

NCAA Division III was chosen for several reasons. First, it represents the largest division in terms of member schools and participant numbers. Second, it strongly emphasizes the athlete's overall human development in contrast to more "elite" sport settings that place more importance on human or financial performance.

Table 1 Participant Background Information

\begin{tabular}{llcc}
\hline $\begin{array}{l}\text { Coach } \\
\text { Pseudonym }\end{array}$ & Sport & $\begin{array}{c}\text { Years in } \\
\text { Coaching }\end{array}$ & $\begin{array}{c}\text { Years in } \\
\text { Current Position }\end{array}$ \\
\hline Bobby & Men's soccer & 10 & 1 \\
Brandon & Men's basketball & 7 & 5 \\
Carlos & Men's soccer & 26 & 7 \\
Christine & Women's soccer & 8 & 8 \\
Gail & Women's basketball & 12 & 12 \\
Hunter & Men's basketball & 21 & 6 \\
Ian & Women's soccer & 20 & 8 \\
Jeff & Men's soccer & 17 & 7 \\
Kasey & Women's basketball & 8 & 8 \\
Luke & Men's basketball & 16 & 9 \\
Lynn & Women's basketball & 7 & 3 \\
Mark & Women's soccer & 9 & 8 \\
Matthew & Women's basketball & 2 & 2 \\
Rob & Men's basketball & 16 & 5 \\
Scott & Men's soccer & 18 & 14 \\
\hline
\end{tabular}


This strongly emphasized role on human development, that is likely implemented through mentoring and role modeling, is probably indicative of most developmental coaching jobs (e.g., high school, youth recreational sport) and helps illuminate contrasts between coaching and other professions where human or financial performance are the primary end products.

Participants were sent an e-mail outlining the purpose of the study and potential interview dates. Then, interview dates and times were established for those who chose to participate (all initial contacts agreed to be interviewed). Interviews were conducted in-person on the respective campuses of the subjects. Interviews were audio recorded and transcribed. Following transcription, member checks were conducted (Janesick, 2000; Neuman, 2000). This process involves sending the participants their transcriptions for reevaluation, so that they can ensure the accuracy of their responses in word and meaning. Appropriate changes were made to the transcriptions following the member check process.

\section{Interview Questions}

The interview questions (see Appendix A) adapted from Herzberg et al. (1957) were used as the basis for inquiry with the coaches. All questions were asked of each participant, yet following a semistructured approach, the researcher and participant were allowed to deviate from these exact questions or question order (Neuman, 2000). This approach allows for a more balanced exchange between the researcher and respondent and opens the way for participants to express the information in their own terms and to expand on areas of importance to them (Neuman, 2000). Using this method, the interview is an active, emergent process whereby the researcher can more concretely understand (rather than necessarily explain) the social world of the respondent (Fontana \& Frey, 2000).

\section{Data Analysis}

Once the interviews were transcribed, two trained researchers independently reviewed them. Using open-coding, "the researcher locates themes and assigns initial codes or labels in a first attempt to condense the mass of data into categories" (Neuman, 2000, p. 421). In this study, the existing literature, with special attention to Herzberg's dual model and Chelladurai and Ogasawara's (2003) Coaching Satisfaction Questionnaire, was used as a starting point for generating themes. It provided the framework for the study and was used initially to "target [the] phenomena under investigation" (Sandelowski, 1993, p. 215). Beyond this literature, the researchers allowed for flexibility and openness to other potential themes (LeCompte \& Preissle, 1993; Neuman, 2000; Strauss \& Corbin, 1998). The two researchers then compared codes until agreement was reached on the themes generated, thus establishing intercoder reliability (Neuman, 2000). Table 2 displays the themes generated through this coding process.

Next, the data were analyzed and coded with an incident approach using QSR International's NVIVO 7 qualitative software. This program allows the researcher to enter codes (generated from theory and initial open-coding), then using Boolean logic or algebra, shows patterns of difference or similarity in the categories of data (Neuman, 2000). The method of agreement (Neuman, 2000) was used for examining similarities in the data gathered. The method of agreement focuses on what 
Table 2 Summary of Coding Themes

\begin{tabular}{|c|c|}
\hline Job Element & Description \\
\hline Flexibility and Control & $\begin{array}{l}\text { Flexibility and freedom to control one's own schedule } \\
\text { and matters related to their team. }\end{array}$ \\
\hline Player-Coach Relationships & $\begin{array}{l}\text { The potential to impact and build relationships with } \\
\text { players. }\end{array}$ \\
\hline Program Building & $\begin{array}{l}\text { The process and achievement of success in developing } \\
\text { a team or program. }\end{array}$ \\
\hline Sport Policy & $\begin{array}{l}\text { The policies, practices, and overall philosophy of uni- } \\
\text { versity and departmental administration. }\end{array}$ \\
\hline Salary & $\begin{array}{l}\text { The financial compensation received for performing } \\
\text { job duties. }\end{array}$ \\
\hline Recruiting & $\begin{array}{l}\text { The task of selecting, soliciting, and obtaining commit- } \\
\text { ments from future student-athletes. }\end{array}$ \\
\hline Personal Life Balance & $\begin{array}{l}\text { The ability to maintain personal responsibilities within } \\
\text { a demanding job setting. }\end{array}$ \\
\hline Quality of Supervision & $\begin{array}{l}\text { The level of leadership, management, and support pro- } \\
\text { vided by the athletic director. }\end{array}$ \\
\hline Relationship with Colleagues & $\begin{array}{l}\text { The affiliation and bond felt between fellow employees } \\
\text { (assistant coaches and other coaches in the depart- } \\
\text { ment). }\end{array}$ \\
\hline Recognition and Social Status & $\begin{array}{l}\text { The external acknowledgment from supervisors, peers, } \\
\text { colleagues, and society based on a coach's job title and } \\
\text { performance. }\end{array}$ \\
\hline
\end{tabular}

is common across cases (see also LeCompte \& Preissle, 1993), such that patterns can be observed without overlooking critical exceptions.

\section{Job Features}

The first step in designing quality products or employment services is to understand expectations of the product or service from the customer or employee perspective. Thus, the primary purpose of this study was to examine the salient job features related to satisfaction and dissatisfaction among a sample of coaches. Table 2 displays a summary of themes that emerged from the interview data. The most frequently mentioned (in terms of incidents) job features reported by the coaches were Flexibility and Control, Player-Coach Relationships, Program Building, Sport Policy, and Salary. Recruiting, Personal Life Balance, Quality and Level of Supervision, Relationship with Colleagues, and Recognition and Social Status were the other job features that were identified.

Each job feature is described below with illustrative quotations from the coaches. Following Miles and Huberman (1994) and Creswell (1998) in attempting to provide substantial description while understanding that not all participants' views can be included, we have provided some context for each quotation (and/or participant) and have chosen quotations that are representative of the entire sample. Where individual quotations are unique or deviate from the general consensus, such deviation is noted (Miles \& Huberman, 1994). 


\section{Flexibility and Control}

It was evident, based on the interviews, that time and schedule flexibility as well as the freedom to control one's own team were vital job features related to coaching satisfaction. These components were combined to form the factor we will refer to as Flexibility and Control. In fact, 12 of the 15 coaches mentioned Flexibility and Control as an important job component related to their satisfaction.

The preference for time and schedule flexibility was salient in almost every interview. In fact, many interviewees even highlighted this as something attractive the coaching industry (particularly at the college level) offers that other industries do not. One coach explained this when comparing his current position to a former position he had held outside of coaching:

Right now the thought of going back to a structure is probably one of the best motivating factors to keep me here. . . . I'm not sure I could go back to that structure. So as bad as this gets [when we lose], I still love having the freedom. (Jeff, men's soccer)

Another coach explained it this way:

I control my own schedule. If tomorrow I wake up and my two children are sick and my wife has to go to work, I can work from home, life is not going to end. Whereas if I'm a lawyer and I've got a trial to do [I cannot do that]. . . . Outside of my specific season, I've got a lot of flexibility over my time and all those things. To me, those are tremendous benefits of what you're able to do. (Luke, men's basketball)

In addition to flexibility in controlling their own schedule, freedom to direct, control, and independently deal with matters related to their own team was also an important job satisfaction factor. Although it was evident that the coaches appreciated having a leader and vocal ally in their athletic director, the less "managing" the coaches received, the more satisfied they seemed with their job. Gail (women's basketball) explained, "Overall, I think I really have a pretty good job. And I'm not micromanaged, which is really a positive. I mean I'm just left alone. . . . I'm just on my own and that's nice." Christine (women's soccer) reiterated this, "I like the freedom that I have here to do my own thing. This has been my program since the day I got [the position]. If we're going to be successful, it's because of me; if we're not, it's because of me." In a candid and frank manner, Bobby (men's soccer) also explained the penchant toward control in his jobs: "I just always kind of gravitated towards leadership roles in some way, shape, or form. And I'm not even certain I could take order all that well."

Conversely, two coaches mentioned that a lack of control or autonomy serves as a source of frustration and dissatisfaction. For example, Scott expressed general frustration with the lack of control over budgets, class schedules, and facility issues, while Luke explained that he felt constantly micromanaged and even undermined in his previous position. He expressed frustration at being told what teams to schedule, which players to play, and how to spend his budget. Very adamantly, he noted that having a plan without the control to achieve it meant defeat of that plan, which made decision-making autonomy not just desired but essential for success. In fact, he felt so strongly about it that he explained that if he had not obtained his current coaching position, he would have left coaching altogether. 


\section{Player-Coach Relationships}

The potential to influence and impact players, serve as a role model, and build meaningful relationships with players were also important factors related to the coaches' satisfaction levels. Thirteen coaches mentioned their most satisfying moments in coaching occurred when they helped players on or off the field of play, develop, and mature. It was common for coaches to indicate the relationship with their players as a reason for staying at their current institution. When asked about job factors that motivate her, Gail (women's basketball) noted, "The kids, first and foremost, are the biggest reason you would stay. You just love the kids; you love to work with them every day." Carlos (men's soccer) also shared these sentiments:

Being able to look out in the field and see a group of guys and say, 'I'm really glad I'm with this particular group of people.' So they might not be the best soccer players in the world and might not have achieved huge successes in terms of winning games, but just to look out there and say, "I like spending time with that kid and that kid and that kid." And that's cool. . . . [I'm] glad that person came into my life and I came into their life. Life is good.

In addition, former players could provide a source of satisfaction especially when they returned to their former coach to acknowledge his or her contribution to their life. For example, Jeff (men's soccer) relayed the following anecdote regarding a former player who contacted him a couple of years after she graduated:

And she called us up and said, "Do you remember when I told you I wasn't going to college? And [you] said, 'Yes, you are,' and then took me to the [career] counselor." Which I didn't remember, but she remembered it, and she said that just changed her life. So, every once in while you'll get one of those. And it doesn't have to be that major, that significant, but that makes you feel good and makes you feel like you've done something in your life.

Nine coaches spoke of former players sharing such milestones as graduations, weddings, starting families, or career promotions, as a source of satisfaction. As Mark (women's soccer) noted, "I like the relationships. I just like to see them as they grow and develop into mature adults."

Occasionally, the coaches mentioned that the Relationships with Players was an element that contributed to job dissatisfaction. For example, Luke (men's basketball) explained:

My first couple of years here were [dissatisfying]. . . . When I first got here with some of the problems, I mean I had two kids arrested the night before we played our first game, my wife's in labor, and this is what I'm dealing with.

This type of situation seemed to occur most often early in a coach's career or after he/she took a position at another institution and inherited another coach's players and recruits. After establishing his/her own program, however, these relationships seemed to serve more as a satisfying element of coaching.

This job feature being mentioned mostly in relation to satisfaction is congruent with a coaching subculture where human development is a central focus (Chalip, 1978; Martens, 2004). These coaches indicate that indeed the opportunity to impact their athletes' lives, not just their athletic careers, is salient to their own feelings 
about their profession. They seem to feel not only a satisfaction with this, but an obligation to develop these young people as citizens and persons. Thus, regardless of performance on the court, the coaches feel good about their jobs if they feel they are doing well at developing humans (e.g., citizenship, maturity, education). This is interesting because it contradicts a claim that coaches only care about winning (e.g., Ryan, 1995; Zimbalist, 1999). Clearly, while some coaches may overemphasize winning, the issue is more complex.

\section{Program Building}

Program Building was identified as a factor important to both job satisfaction and dissatisfaction. The theme of Program Building captures both the process and the results coaches strive for in achieving success in their careers. While it is not surprising that coaches would suggest that winning would enhance their satisfaction, the coaches in this study expressed that the process of program building was as important as victorious outcomes. In fact, all 15 coaches made mention of the importance of the process involved in building a sport program. A plethora of program developing and building analogies were used to describe satisfying moments in one's coaching profession. For instance, comparisons to "fighting an uphill battle," "putting together a puzzle," "building a structure from the ground up," and "executing a business plan" were just a few of the program building metaphors that emerged from the interviews. The coaches then followed these analogies with comments related to the satisfaction they felt when a strategy or the team they formed came together. "Figuring it out was great because I didn't mind working at all. I didn't mind coming here and working all of those hours" (Lynn, women's basketball). One coach further explained this by recounting a recent conversation she had with an assistant coach who was new to the industry:

I said [to him], "Could you imagine being anywhere else doing anything else at this moment? ... Look at those guys. Don't you love what you do?" And it's like just watching them do everything that we've done in training, everything that we've talked about and seeing them take the training and put it on the field. And I said, "This is why you do what you do." (Christine, women's soccer)

This drive keeps Mark (women's soccer) satisfied at his current institution: "I really enjoy coaching here; building a program from the ground floor up and all that work that I've put into developing this women's soccer program is not something that I want to walk away from for just anything."

The challenge and competitiveness of building a sport program was noted in the interviews as a significant job feature impacting a coach's desire to stay in the profession. Kasey (women's basketball) noted, "The biggest thing that makes me want to stay is that I want my self-satisfaction to know that I can build this program to where I feel like it's respectable." In fact, some coaches seemed not only to derive satisfaction, but to actually thrive on the pressure and competitiveness of their position.

I love being just the person who makes the decisions in a split second and it's on me. If it's wrong, it's on me; I learn from it. If it's right, I love that. I love that feeling and I mean you can't get that from anything else. (Lynn, women's basketball) 
This internal persistence and determination in accomplishing a feat and seeing a plan come to fruition contributed to satisfaction and possibly even to career retention.

Although most coaches felt that successful program building was a source of satisfaction, it was certainly dissatisfying when it was not present. Hunter (men's basketball), for example, verbalized this when speaking of his current job satisfaction compared with a prior coaching position he had held:

I think that part of it, [is] the satisfaction of knowing the team has reached close to its potential. And probably the other part of it is the togetherness of the group, the way the team came together. I've been very fortunate relative to just how close a unit I've had for the last eight years of coaching. Because when I think back ten years ago and the conflicts and the turmoil that went on with group dynamics, it made it the opposite.

Similarly the external pressure in the profession to produce winning outcomes, especially without regard to the process, may cause dissatisfaction and push a coach toward different career altogether. Gail (women's basketball) explained, "I think the tough part about coaching is that your livelihood depends on eighteen to twentyone-year-olds and they're not always reliable. And they definitely shouldn't be in charge of whether you have a job the next year or not." Kasey (women's basketball) agreed with this outlook, "The negatives are always losing [and the] pressure-one of the biggest things is the pressure of winning and everyone deals with that." In fact, even after reaching a major milestone and finally securing national prominence, one coach's description of his emotions supports this idea:

I can guarantee that I wasn't feeling good right at the end of it, more than anything it was just feeling relieved. Relief was the only emotion. I mean as soon as the game was over, I just couldn't wait to get back to the hotel, take a shower, sit on the couch and say, "Okay, stop." .. . It was just relief. (Scott, men's soccer)

This coach, rather than feeling excitement over winning, actually only felt relief from the pressure he had been under for almost the three years it took to build a successful program.

The job feature of Program Building is not surprising in a coaching subculture where coaches expect to work hard and sacrifice greatly to achieve success (Dixon et al., 2006; Hughes \& Coakley, 1991). Coaches derive a sense of satisfaction, to a point, from aggressively pursuing success both in terms of teambuilding and actual victories. Their dissatisfaction can stem from a feeling of not being able to bring together their team or it can also come from a felt pressure to win without regard to the process. Further, there seems to be some sense of a limit to the pressures they expect to face especially with regard to the resources they are given to succeed. In that sense, it may be that satisfaction levels are tied to a match between their own expectations of success and those of the university community where they are employed.

\section{Sport Policy}

The overall athletic philosophy of the university (i.e., Sport Policy), was another commonly mentioned job feature. Interestingly, this job feature was most often 
mentioned in concert with times the coaches felt dissatisfied with their jobs. In fact, interviews revealed elements such as the "constant battle for credibility [and] for respect" could cause such dissatisfaction that coaches would seek new positions at institutions with policies and administration that were more supportive of athletics. Carlos (men's soccer) articulated this when speaking of his frustration and the influence that Sport Policy can have on a coach:

I think the really hungry, go-getter, I want to get after it, coaches come in and say, 'This isn't the place.'. . . I'm not sick of coaching at all. I would say it's the [administrative] environment. And the expectation or lack thereof.

Gail (women's basketball) added, "People leave [coaching] positions because they get frustrated with the way things are and the lack of change and the lack of advancement and the lack of achieving new goals and striving for new things and fighting for the big picture."

These comments were representative of a number of coaches who felt their administration had grown complacent. Interestingly, the coaches were frustrated not because of too great a demand for excellence, but too little. Complacency seems to go against the subculture within coaching of winning, achievement, and sacrifice. Equally frustrating seemed to be the situation where coaches were pressured to win without being given the financial and human resources (e.g., assistant coaches) to do so. Thus, the individual job features of Player-Coach Relationships, Program Building, and Sport Policy may all have a distinct relationship to job satisfaction and/or dissatisfaction, but the match (or mismatch) between coaches' expectations of themselves and the expectations of the university community create a possible additional dynamic related to job attitudes. Based on the interviews, high self expectations coupled with low administrative expectations or high self-expectations coupled with lack of resources, seemed to be a key-contributing factor both to job dissatisfaction and to job exit.

\section{Salary}

The next factor, Salary, also seemed to be mentioned mostly in the dissatisfaction context. Of the 15 coaches interviewed, 12 explicitly expressed they felt they were not paid enough. Even though most expressed that salary contributed to dissatisfaction, it appeared as though those interviewed did not expect the coaching profession to be a lucrative career and recognized the financial limitations. For example, Kasey (women's basketball) stated, "You know and I know that we [coaches] could be making a whole lot more money doing something else and probably putting in a lot less hours."

Although Salary seemed to be an element causing dissatisfaction, often times any mention of Salary was quickly tempered with an expression of devotion to the job itself.

Well, the financial side of things for sure is a limitation. And everybody's situation is different. I think really, it's an individual situation.... So, at some point if your income was not sufficient and you have to start making that decision of do I have to leave and go find another job at another school with better pay or do I have to just leave coaching and go to a different profession all together? ... I love working here. I love Division III and what it represents. Financially, 
though, it's very restrictive to stay here. I can't retire here. (Brandon, men's basketball)

Bobby (men's soccer) further illustrated this devotion, regardless of compensation, many coaches expressed toward their occupation:

I joke that I've been employed for ten years, but I haven't worked but a few days. The reality is that it's a vocation that I enjoy, it's not a job; it's something that you don't have a sense that I'm dreaming about retiring from the standpoint that if I had enough money to not have to work, there's about a 99\% chance that I'd still have a soccer team. I mean if I won the lottery I don't think that I'd quit this job.

These representative statements seem congruent with a human development perspective on sport. That is, the coaches indicated that they are mostly motivated to work by the opportunities for human development and impacting people's lives, not by the monetary compensation they receive. Still, they expected to receive at least reasonable compensation for their work, especially relative to the hours they invest. The majority of the coaches interviewed, therefore, viewed Salary not as a feature that would lead to satisfaction, but rather as one that would lead to dissatisfaction.

\section{Recruiting}

A large portion of the coaches' time was spent on recruiting athletes to their respective universities. The coaches agreed that recruiting was an essential part of their job because it helps justify that athletics can play an integral part of a university and, obviously, recruiting determines the make-up of their teams with whom they will be working on a daily basis. Yet, interviewees clearly indicated they were not in the coaching profession because of the opportunity to recruit athletes. "Recruiting isn't fun. Don't get me wrong, I'd rather do that than sit in an office. . . . But I mean, compared to being on a court with my team, it's night and day. It's not even close" (Matthew, women's basketball). Recruiting appeared to be a necessary yet dreadful duty rather than an appealing part of a coach's job.

Seventy percent of this job is recruiting. And I'm at Division III; I can't imagine what it's like at Division I. So it's getting e-mails, sending back e-mails, making phone calls, getting back with anyone who calls you, talking to parents, when people come and visit, visiting with them, going to tournaments, observing players, writing letters, and then waiting for those responses, and then filing that. I mean just the administrative stuff that goes with that in getting the responses, filing, putting them in your computer so you have a list, trying to keep track of which players potentially might want to come here, especially because you have to match that here at this school. (Ian, women's soccer)

Recruiting was consistently reported as being time intensive and tedious. In addition to the actual task of recruiting, NCAA policies and the lack of institutional support in recruiting of student-athletes were commonly noted as specific factors that led to Recruiting being a dissatisfying job element.

From a job preference perspective, recruiting was discussed as passionately as the ability to impact athletes; however, in the opposite direction. That is, as passionately as they spoke about enjoying the relationships with current athletes, they spoke with equal distaste about recruiting. One likely explanation of this is that coaches 
must yield control of the recruiting process ultimately over to the prospective athlete and the university admissions process. Unlike other aspects of their job, the coach could spend a tremendous amount of time and effort in recruiting and not obtain desired results due to external factors such as financial need or admission standards. Thus, the lack of control could lead to dissatisfaction. Given the obvious saliency of this job facet, it is noteworthy that previous studies have not included this element in their assessments of college coaching job satisfaction. This is important because it shows an area that can be overlooked by researchers when they only consider levels of satisfaction rather than considering satisfaction and dissatisfaction.

\section{Personal Life Balance}

Aspects relating to one's personal life, such as social network and family, also emerged from the interviews. Nontraditional work hours, extensive travel, and overall large time commitment are ingrained in the coaching profession and were expected and acknowledged by all of the coaches. They were not dissatisfied by working long hours or travel, per se. However, they were concerned about finding a balance between work and their personal lives. Not surprisingly, Personal Life Balance was reported as an important job consideration usually associated with dissatisfaction. Matthew (women's basketball) spoke frankly about his future and having to balance his personal life, "If I ever want to start a family, I've got to get out of this [particular coaching position]." Matthew felt in his current position he would not be able to balance the workload and adequately support a family. His straightforward response implied Personal Life Balance is an essential job factor. Lynn (women's basketball) shared similar sentiments:

The only thing would be my family ... that's why I would leave coaching. It's a part of me; I love it, but my family comes first. And when my job is coming before family, that's when I will say, "Forget it; it's not worth it."

Hunter (men's basketball) further echoed the value he places on his family's preferences: "What keeps me here is the happiness of my family, whether it be this job or [another]. My family is happy so that keeps me happy and allows me to continue to do what I am doing." This comment seems to indicate that Personal Life Balance was integral and had a large influence on whether a coach stayed in his or her current position and, even more importantly, whether they remained in coaching profession.

\section{Quality of Supervision}

The Quality of Supervision, particularly as it related to that of the athletic director, also materialized in the interviews. Supervision was a noted catalyst for frustration and dissatisfaction, and seemingly had the potential to cause coaches to leave their current position.

I think another thing that would make me leave would be continued devaluation of my relationships as they develop with my athletic director and dean of students and vice-president, who all seem to be in the mix. ... So I think the relationship you have with your athletic director and who he reports to; if your ducks aren't lined up, you're [going to] have problems. (Rob, men's basketball) 
Further, when Gail (women's basketball) was asked about moments she felt dissatisfied in her job, she said, "A big source of frustration is consistency [from the athletic director] and also, probably the largest one is treating everybody the same and fairly." Luke (men's basketball) explained his biggest frustration was doing his job well only to have his athletic director ask him to "do three other things to prove that I'm doing what I'm supposed to be doing." This obvious lack of quality supervision contributed in all three cases to job dissatisfaction.

\section{Relationships With Colleagues}

Relationships with Colleagues was another job feature that emerged from the interviews. The coaches indicated that camaraderie and a sense of community within their department could serve as a source of satisfaction. Further, it may be a distinguishing factor between those coaches who perceived themselves to be in a "good" job and those who identified themselves as having a "great" job. The following three examples illustrate this factor:

And that camaraderie is one of the special things about the Division III situation because it's got to be difficult to be at a school where you're the track coach and you're making $\mathrm{x}$-amount of money and the football coach is making two point something million dollars. You know you're working just as hard. . . . It should be more of a camaraderie type of an environment where, it's "us against them" attitude as opposed to an "us against us" type thing. I've been in departments [without that camaraderie]; it's not fun to be around, it's not fun to be walking down the hall and all the doors are closed. (Luke, men's basketball)

I've been fortunate in the situations I've been in to work. I've always worked with good people and been around good people. And that's the same thing here . . . is that normal? I don't think it is. . . I think the youth of the staff allows us to have that camaraderie because I know a lot of times that's not the case and it's nice when it is. So it certainly helps. I enjoy it and am planning on staying in it. (Brandon, men's basketball)

One [thing that makes me happy] is, in this job, the people around here, my peers, there is some cohesiveness and some commonality and goals. I think that makes the workplace an enjoyable place to hang out. It's funny because I can't think of a day in the last ten years where I've said, 'Oh, God, I don't want to go in the office.' (Hunter, men's basketball)

Like the relationships that coaches built with some players, Relationships with Colleagues have the potential to be just as meaningful and contribute to job satisfaction or dissatisfaction.

The saliency of these relationships is a job feature not unique to, but certainly highlighted in, a coaching setting, particularly at Division III where jobs often overlap. The expectation that coaches would have a camaraderie and sense of teamwork most likely comes from the overall culture of sport as a site for learning teamwork and working with others (Hughes \& Coakley, 1991). This expectation in coaching is probably different from other professions where there is more independence and/ or internal competition rather than cooperation, and therefore could elicit a different relationship to satisfaction/dissatisfaction than other contexts. 


\section{Recognition and Social Status}

Recognition from administration and peers and the Social Status from working in the coaching profession was the final theme to emerge from the interviews. It was apparent that the coaches did not expect any external feedback or to be recognized for their efforts, but did appreciate any acknowledgment from institutional representatives or coaching peers. Telephone calls after a big win, emails and notes of appreciation, along with conference coaching awards all served as an unexpected yet welcomed job feature which contributed to a coach feeling satisfied. "I think the [acknowledgement] from the university community means a lot. I would say one to ten, it is a ten, a ten is the best (Gail, women's basketball)." Ironically, only five coaches reported that they had received such recognition.

The social status that can result from serving as a head coach also acted as an attractive job element.

Well I think that one of the things that I like is I think there's a certain notoriety that goes along with coaching. I guess when people call me "Coach"; it's a good feeling. I think that there's a certain notoriety and respect that comes from that. I kind of liken it to when people call people "Doctor." I think that's a very respectful position in our society and I think people, in general, are responsive to people who are in my field. So I like that aspect of it. (Rob, men's basketball)

Bobby (men's soccer) admitted, “There is some egocentrism in that, I just kind of like being a college coach, relative to being a club coach." Although this element was only mentioned by four coaches, it appears that they see a definite distinction between coaching at the college level and other levels. These coaches indicated that Recognition and Social Status were not necessarily anticipated job features, yet both seemed to be welcomed and appreciated. This indicates that coaches do not require recognition, but thrive when it is appropriately given.

\section{Model of Satisfaction and Dissatisfaction}

Results from the coaches' rich description of their job experience reveal that coaching is a complex and multifaceted profession and these different job facets have varied and dynamic relationships to both satisfaction and dissatisfaction. In terms of the actual job features that relate to job satisfaction, our results somewhat coincide with previous studies on job satisfaction (e.g., Chelladurai \& Ogasawara, 2003; Raedeke et al., 2002; Weiss \& Stevens, 1993). That is, Flexibility and Control, Program Building, and other job features do appear to impact coaching satisfaction. Beyond these specific features, however, this study is even more concerned with coaches' patterns of reactions to whether those specific features are fulfilled or not fulfilled in their current positions. Examining these patterns allows us to develop a picture of the interaction among job features with employee expectations in a coaching context. Further, it allows us to see how coaches' respond to feeling satisfied or dissatisfied (e.g., do they work harder? Leave their position?). Understanding these consequences is vital not only to managers, but also to the sport industry as a whole. 
Building from these data as well as Herzberg's and Kano's models, a threefactor coaching satisfaction model emerges (see Figure 1) that shows how various employment features in coaching relate to both satisfaction and dissatisfaction as they are filtered through employee expectations. That is, the relationship of specific job features to satisfaction or dissatisfaction seems to be dependent on the coaches' expectations of the job and on whether those expectations are met.

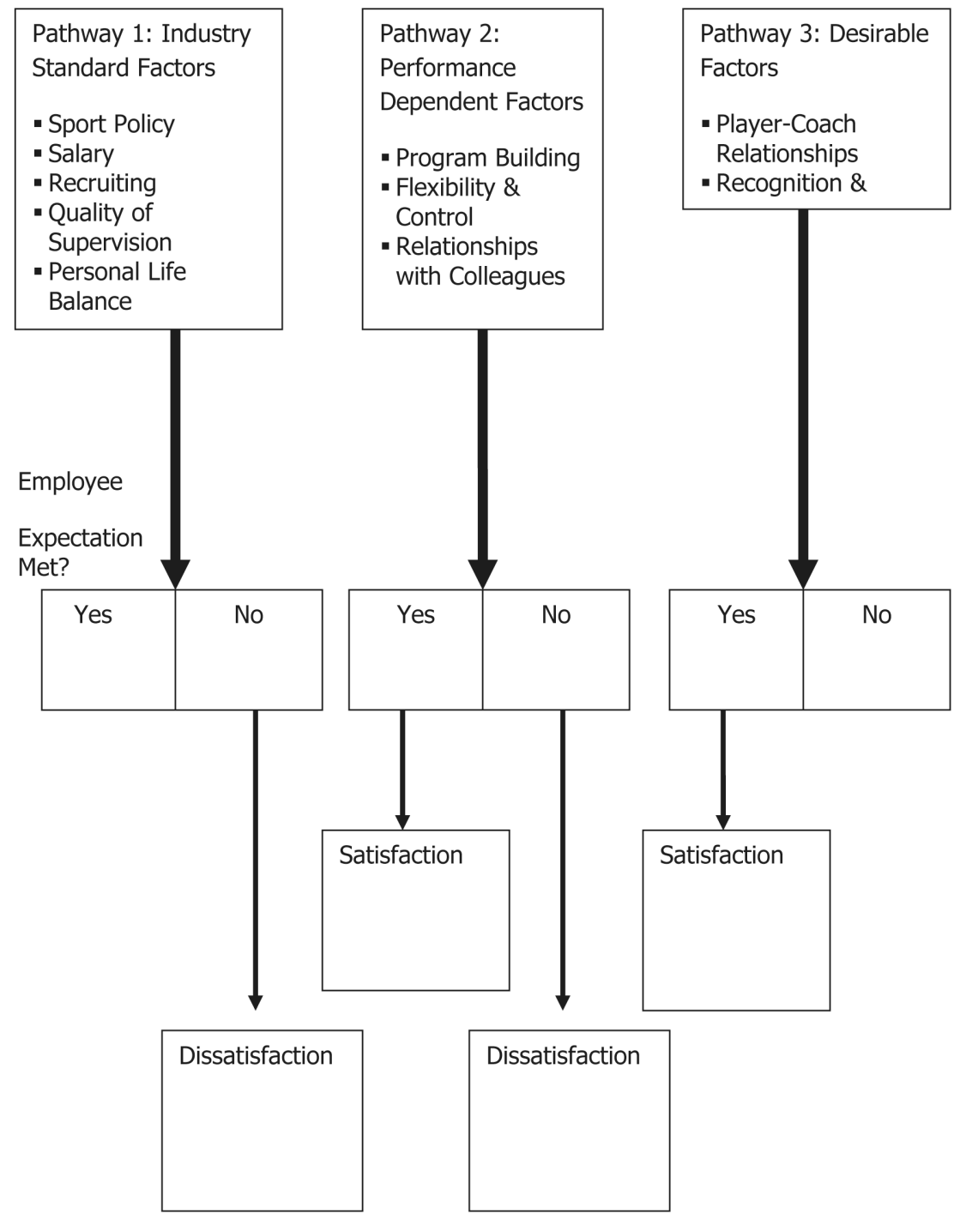

Figure 1 - A multidimensional model of coaching satisfaction and dissatisfaction. 


\section{Industry Standard Features}

Industry Standard Features (see Pathway 1 in Figure 1) are certain job features employees expect to be present in basically any coaching job. When these job element expectations are not met, employees express dissatisfaction and often intent to leave their current job; when expectations are met, the employee attitude is neutral. For example, the coaches interviewed have an expectation of working for an institution with supportive sport policies, and one with high expectations of their athletics programs (i.e., one that matches their own high expectations). Therefore, when the administration is supportive, the coaches are not necessarily satisfied, but feel this is status quo. However, when the administration is not supportive, it is a source of great dissatisfaction, with several coaches indicating they had and would search for positions where the administration was more supportive. The same pattern is seen in job features related to salary and recruiting. The coaches expect a certain (albeit low) level of salary and support for their recruiting responsibilities. When this level is met, the employees express neutrality. However, when these expectations are not met, employees express dissatisfaction and an intent to search for other positions (both inside and outside of coaching).

\section{Performance Dependent Features}

The second pathway depicts types of job features that can lead to either satisfaction or dissatisfaction dependent upon whether the coaches' expectations are met. When expectations are met, coaches express satisfaction; when expectations are not met, coaches express dissatisfaction. Flexibility and Control, Program Building, and Relationships with Colleagues are all job features in coaching that seem to be performance dependent, whereby coaches express satisfaction and loyalty to their current position or team if their expectations are met, but seem equally quick to express dissatisfaction and desire to change jobs if expectations are not met. For example, Program Building was the most frequently reported job factor related to satisfaction. This finding generally concurs with Chelladurai and Ogasawara (2003) who noted Team Performance was related to coaching satisfaction. Unlike their study, however, our findings revealed that coaches whose jobs were lacking in success-either in outcome, or more importantly in process-also reported dissatisfaction. In fact, a number of the coaches in this study claimed that lack of success at a previous position led them to leave that position for their current one.

Further, while there often seems to be a perception that coaches only care about winning or losing, the coaches in this study strongly emphasized that in addition to player-coach relationships, the teambuilding process is as important, if not more important than game outcomes. Their satisfaction stemmed from the coming together of a team, a sense that the team "understood" the goals or "bonded" in pursuit of something larger than their individual efforts. While there may be some greater sense of this teambuilding principle in the particular sample, as it only included coaches of team sports, this finding points to the need for greater exploration of the processes in coaching rather than only the outcomes. The sport management literature has done little to examine how elements such as sport type, sport level, and performance management systems relate to coaches' perceptions of the importance of process versus outcome and how that relates to how they feel about their jobs. Findings from this study, from a practical standpoint, also demonstrate 
the need for administrators to move beyond a focus on just wins and losses, but to also recognize, support, and reward the efforts that go into the process of teambuilding (cf. Cunningham \& Dixon, 2003). This shift in focus could have a great impact on increasing the satisfaction and reducing the dissatisfaction of coaches.

Performance Dependent job features, as a group, also highlight the dynamic nature of satisfaction and dissatisfaction in that coaches' reactions to their jobs are not based on some absolute level of success, control, or relationship quality, but on how well those elements match their expectations. For example, a new coach may have a lower expectation of work hour flexibility and, therefore, express less dissatisfaction when asked to hold office hours or make reports to his/her supervisor. A more established coach, however, may expect more control over his/her time and decisions and, therefore, express extreme dissatisfaction when that flexibility and control is squelched. Thus, it appears that the relationship between various job features and both satisfaction and dissatisfaction are not static, but are time and context specific.

\section{Desirable Features}

The third type of job feature that emerged from our data are "Desirable Job Features." These features, when coaches' expectations are met, lead to satisfaction; when not met, they lead to neither satisfaction nor dissatisfaction. That is, perhaps these are features where coaches usually expect some variation in fulfillment, such that when the job element is fully realized it noticeably adds satisfaction to their jobs. For example, the job feature of Recognition and Support appears to be a Desirable Job Feature in coaching. When coaches do not receive recognition, they are neutral, but when they do receive recognition, they are very satisfied.

\section{Theoretical Implications}

The emergent model of coaching satisfaction extends previous contentions that satisfaction and dissatisfaction are not necessarily opposite ends of the same continuum. That is, while Herzberg suggested that job features lead only to satisfaction or dissatisfaction, our findings are more congruent with Kano (1984) where some job features only lead to satisfaction, some only to dissatisfaction, and some to either/or. The evidence that satisfaction and dissatisfaction are not always opposites indicates the need to include measures of both satisfaction and dissatisfaction in examining employee attitudes. It also points to the need to further examine the relationship of each construct to employee behaviors. For example, the coaches in this study indicated that dissatisfaction would lead to job search behaviors. Does only dissatisfaction elicit such behavior? In addition, what is the relationship of satisfaction and dissatisfaction to employee performance? While satisfaction has been shown to have a weak, but consistent positive relationship to performance (Judge et al., 2001), it is not known if dissatisfaction necessarily leads to poor performance.

These findings are also important to theory because they acknowledge that satisfaction is not static; situation, context, job market characteristics, and employee expectations all influence the relationship between job elements and employee attitudes (see also Matzler et al., 2004). This is seen in the actual job factors that operate according to the three pathways. 
Quality of Supervision, Salary, and Sport Policy are Industry Standard factors. These are similar to hygiene factors or "Must-be" factors found in other studies (Herzberg et al., 1959; Kano, 1984; Matzler et al., 2004). That is, fulfilled expectations of these factors lead to neutrality, but unfulfilled lead to dissatisfaction. However, Recruiting and Personal Life Balance are additional Industry Standard factors that are unique to this study and seem particularly salient to coaches. Interestingly, coaches do not seem to have high expectations of personal life balance, but in the absence of even a semblance of balance, they express dissatisfaction and a desire to change jobs or careers (see also Dixon \& Bruening, 2007). Clearly these are job features that deserve more attention in sport contexts as they impact employee attitudes and behavior.

One of the most interesting findings from this study relates to the theme of Sport Policy. While we are cautious about the generalizability of qualitative research (Denzin 1989; Guba \& Lincoln, 1981), from a broader perspective, the findings on Sport Policy from this study further highlight the tension between athletics and education in settings where athletics are housed in educational institutions. This tension is often more obvious at the Division I level, where academic success and graduation rates have been a source of debate especially in revenue generating sports (e.g., Zimbalist, 1999). While at the Division I level the tension seems to stem from too much pressure on winning, the coaches in this study expressed a frustration with expectations that were too low. In terms of satisfaction and dissatisfaction, this is a difficult issue both theoretically and practically. More specifically, how can one have enough pressure and high enough expectations such that they feel their work is valuable and important, yet not so much pressure or expectation that they feel overwhelmed by it? Certainly this is not a new issue, yet one that deserves careful consideration of context and of a fit or match between employee and organizational goals, needs, and values.

Flexibility and Control, Program Building, and Relationships with Colleagues appeared to be Performance Dependent factors. Herzberg viewed similar factorsautonomy, challenge, achievement, job variety - as motivational factors, meaning they were only associated with satisfaction. By contrast, the coaches in this study explained that their satisfaction or dissatisfaction was dependent upon the levels of program building, control, and pressure as compared with their expectations. If they were successful in building their team to their expected level, had sufficient control over their jobs, experienced sufficient pressure, to name a few, then they expressed satisfaction. If they experienced too much pressure or too little achievement in building a program, for example, then they expressed dissatisfaction. That these factors operate as Performance Dependent is definitely a finding worth further exploration and explanation as it appears that coaches' reactions to these features are not just toward satisfaction, but can also quite readily lead to dissatisfaction.

Player-Coach Relationships and Status and Recognition operated as Desirable Factors. Interestingly, Herzberg et al. (1959) classified recognition as a pure motivator, while Matzler et al. (2004) found it to be unrelated to either satisfaction or dissatisfaction. In this study, it operated similar to a motivator, leading only to satisfaction, but not to dissatisfaction, which again points to the need for industryspecific examinations. Player-Coach Relationships was a feature that emerged from this study and seems to be a unique and highly desirable element of coaching. While this is not surprising given the centrality of human development in some coaching 
subcultures, it certainly merits further exploration especially in comparison with other professions and perhaps even other more elite coaching contexts.

This study identified a number of areas that coaches may have expectations from their job or employer that may differ from other professions. It also showed how attitudes are dependent upon expectations, which can change, rather than an absolute level of any given job element. Understanding the dynamics and expectations of employees within a specific profession helps us continue to develop theory appropriate to that profession.

\section{Practical Implications}

From a practical human resource management perspective, these findings are important because they help managers (especially athletic directors) better diagnose and solve employee issues (Matzler et al., 2004). As Matzler et al., (2004) and Martensen and Gronholdt (2001) pointed out, understanding employee needs and wants from their perspective helps managers focus on the job elements that most contribute to positive employee outcomes; and how can one know which elements are important without asking the employees themselves? It also shows managers how expectations can change and that they need to maintain tracking tools to monitor coaches' expectations and the various job elements that are important to them.

Using the model developed in this study as a practical tool, it appears that coaches expect quality supervision, recruiting support, a reasonable salary, and a supportive administration. Attention to these job factors will keep coaches from being dissatisfied and searching for other employment. Enhancing these elements, however, will probably not highly motivate coaches. Conversely, coaches who have high quality relationships with their athletes report high levels of satisfaction, so removing barriers to make this happen could help attract and retain coaches. Finally, performance-related elements such as opportunities for building a program, control, and pressure directly impact coaches' feelings about their jobs. Managers should closely monitor employee expectations and reactions toward these elements as they can lead to large swings in satisfaction and dissatisfaction.

\section{Conclusions and Directions for Future Research}

In conclusion, this study was concerned with examining job features related to the satisfaction and dissatisfaction of college coaches. Results revealed that coaching is a complex and multifaceted profession and these different facets have varied and dynamic relationships to both satisfaction and dissatisfaction. The study extended previous research in sport management by examining not only what job features are particularly important to coaches, but also how the fulfillment (or not) of job features impacts coaches' attitudes. It demonstrated the need for continued examination within specific industries regarding the salient expectations and job factors that mesh to form satisfaction and dissatisfaction.

Future research should extend and test these findings in a number of ways. First, the sample within this study provided in-depth information, yet was from a small subset of coaches. Future study will need to expand the size and breadth of the sample to examine both the model pathways and the job features proposed in the current study especially with regard to coaching jobs at the more elite and/or 
professional levels. This will help continue to uncover job features that are more general and those that are industry-specific.

Second, many have argued that because of the strong gender expectations in, and surrounding, sport, any examination of a sport context must be done with an awareness of gender issues (e.g., Dixon \& Bruening, 2005, 2007; Inglis et al., 2000; Knoppers, 1992; Messner, 1992). The responses from the participants in the current study did not reveal any significant relationships between gender and satisfaction or dissatisfaction on any of the specific job features. However, that does not mean that those relationships do not exist. Future inquiry with a larger sample may bring such relationships to light and demonstrate how gender of the coach and/or program influences expectations, fulfillment of those expectations, and the accompanying attitudes and behaviors of coaches.

Third, the qualitative information from this study forms a basis for exploring trends and grounding a theoretical model. That model, however, needs to be tested to verify the pathways. Kano (1984) and others (e.g., Berger et al., 1993) have developed quantitative methods for such testing that involve paired questions for customers. In each pair, the customer is asked his/her reaction if a product element is fulfilled, then the customer is asked if the product element is unfulfilled. Such questions could be developed for the sport industry and its specific segments that would be relevant to the needs and expectations of coaches, administrators, and front office personnel. These questionnaires would be useful for theory building and would also provide a practical diagnostic tool for managers.

Fourth, although this study revealed the most frequently mentioned and passionate responses, it did not determine importance rankings per se. Future study should examine the importance of various job features in combination with expectations. For example, if a job element acts as a Performance Dependent feature, yet is not highly valued by the coaches, it may have little impact on their satisfaction or dissatisfaction. However, if it is highly valued and Performance Dependent, then it would be critical to subsequent attitudes and demand attention from human resource managers and/or athletic directors. Determining expectations and importance would not only help guide theory, but have strong practical implications as well.

\section{Notes}

1. Kano's work is written in Japanese. Therefore, while acknowledging the original source of the model, the current study relies on English adaptations of his original work, which mainly have been adopted in the Total Quality Management literature.

\section{References}

Berger, C., Blauth, R., Boger, D., Bolster, C., Burchill, G., DuMouchel, W., et al. (1993). Kano's methods for understanding customer-defined quality. Center for Quality of Management Journal, 2, 3-30.

Brown, M., \& Little, B. (2001). One heartbeat. New York: Bright Sky Press.

Butterfield, L.D., Borgen, W.A., Amundson, N.E., \& Maglio, A.T. (2005). Fifty years of the critical incident technique: 1954 - 2004 and beyond. Qualitative Research, 5, 475-497.

Chalip, L. (1978). Role conflicts in a coaching subculture. In J. Hinchcliff (Ed.), The nature and meaning of sport in New Zealand (pp. 62-65). Auckland, NZ: University of Auckland. 
Chalip, L. (1990). Rethinking the applied social sciences of sport: Observations on the emerging debate. Sociology of Sport Journal, 7, 172-178.

Chalip, L. (1997). Action research and social change in sport. Journal of Sport Management, 11, 1-7.

Chalip, L. (2006). Toward a distinctive sport management discipline. Journal of Sport Management, 20, 1-20.

Charmaz, K. (1990). Discovering chronic illness: Using grounded theory. Social Science \& Medicine, 30, 1161-1172.

Chelladurai, P., \& Ogasawara, E. (2003). Satisfaction and commitment of American and Japanese collegiate coaches. Journal of Sport Management, 17, 62-73.

Coakley, J.J. (1986). Sport in society: Issues and controversies. St. Louis, MO: Times Mirror/ Mosby College Publishing.

Creswell, J. (1998). Qualitative inquiry and research design: Choosing among five traditions. Thousand Oaks, CA: Sage.

Cunningham, G., \& Dixon, M. (2003). New perspectives concerning performance appraisals of intercollegiate coaches. Quest, 55, 177-192.

Currivan, D. (2000). The causal order of job satisfaction and organizational commitment in models of employee turnover. Human Resource Management Review, 9, 495-524.

Denzin, N. (1989). Interpretive interactionism. Newbury Park, CA: Sage.

Dixon, M.A., \& Bruening, J.E. (2005). Perspectives on work-family conflict in sport: An integrated approach. Sport Management Review, 8, 227-253.

Dixon, M.A., \& Bruening, J. (2007). Work-family conflict in coaching I: A top-down perspective. Journal of Sport Management, 21, 377-406.

Dixon, M.A., Bruening, J.E., Mazerolle, S.M., Davis, A., Crowder, J., \& Lorsbach, M. (2006). Career, family, or both? A case study of young professional baseball players. Nine: A Journal of Baseball History and Culture, 14(2), 80-101.

Dixon, M.A., \& Pastore, D.L. (2003). An Empirical investigation of the satisfaction, commitment, and performance of NCAA Division III coaches. Research Quarterly for Exercise and Sport, 74(Supplement), 85.

Doherty, J.K. (1985). Track and field omnibook. Mountain View, CA: Tafnews Press.

Edvardsson, B. (1992). Service breakdowns: A study of critical incidents in an airline. International Journal of Service Industry Management, 3(4), 17-29.

Edvardsson, B. (1998). Causes of customer dissatisfaction—studies of public transport by the critical-incident method. Managing Service Quality, 8(3), 189-197.

Edwards, A. (1999). Reflective practice in sport management. Sport Management Review, 2, 67-81.

Flanagan, J.C. (1954). The critical incident technique. Psychological Bulletin, 51, 327-358.

Fontana, A., \& Frey, J. (2000). The interview: From structured questions to negotiated text. In N.K. Kenzin \& Y.S. Lincoln (Eds.), Handbook of qualitative research (2nd ed., pp. 645-672). Thousand Oaks, CA: Sage.

Friedlander, F. (1964). Job characteristics as satisfiers and dissatisfiers. The Journal of Applied Psychology, 48, 388-392.

Geertz, C. (1973). The Interpretation of culture: Selected essays. New York: Basic Books.

Green, B. (2001). Leveraging subculture and identity to promote sport events. Sport Management Review, 4, 1-19.

Guba, E.G., \& Lincoln, Y.S. (1981). Effective evaluation: Improving the usefulness of evaluation results through responsive and naturalistic approaches. San Francisco: Jossey-Bass.

Hallowell, R., Schlesinger, L.A., \& Zornitsky, J. (1996). Internal service quality, customer and job satisfaction: Linkages and implications for management. Human Resource Planning, 19, 20-21.

Herzberg, F. (1966). Work and the nature of man. New York: Cromwell.

Herzberg, F. (1968). One more time: How do you motivate employees? Harvard Business Review, 46, 53-62. 
Herzberg, F., Mausner, B., Peterson, R., \& Capwell, D. (1957). Job attitudes: Review of research and opinion. Pittsburgh, PA: Psychological Services of Pittsburgh.

Herzberg, F., Mausner, B., \& Snyderman, B. (1959). The motivation to work. New York: John Wiley.

Hughes, R., \& Coakley, J. (1991). Positive deviance among athletes: The implications for overconformity to the sport ethic. Sociology of Sport Journal, 8, 307-325.

Hulin, C., \& Smith, P. (1967). An Empirical investigation of two implications of the twofactor theory of job satisfaction. The Journal of Applied Psychology, 51, 396-402.

Ilgen, D., \& Hollenbeck, J. (1991). The Structure of work: Job design and roles. In M. Dunnette \& L. Hough (Eds.), Handbook of industrial and organizational psychology (2nd ed., pp. 165-208). Palo Alto, CA: Consulting Psychologists Press.

Inglis, S., Danylchuk, K., \& Pastore, D. (2000). Multiple realities of women's work experiences in coaching and athletic management. Women in Sport and Physical Activity Journal, 9, 1-26.

Janesick, V.J. (2000). The choreography of qualitative research design: Minuets, improvisations, and crystallization. In N.K. Kenzin \& Y.S. Lincoln (Eds.), Handbook of qualitative research (2nd ed., pp. 379-400). Thousand Oaks, CA: Sage.

Judge, T., Thoresen, C., Bono, J., \& Patton, G. (2001). The job satisfaction-job performance relationship: A qualitative and quantitative review. Psychological Bulletin, 127, 376-407.

Kano, N. (1984). Attractive quality and must-be quality. The Journal of the Japanese Society for Quality Control, 14, 39-48.

Kellett, P. (1999). Organisational leadership: Lessons from professional coaches. Sport Management Review, 2, 150-171.

Knoop, R. (1994). Work values and job satisfaction. The Journal of Psychology, 128, 683-689.

Knoppers, A. (1992). Explaining male dominance and sex segregation in coaching: Three approaches. Quest, 44, 210-227.

LeCompte, M.D., \& Preissle, J. (1993). Ethnography and qualitative design in education research (2nd ed.). San Diego, CA: Academic Press.

Li, M. (1993). Job satisfaction and performance of coaches of the spare-time sports schools in China. Journal of Sport Management, 7, 132-140.

Martens, R. (2004). Successful coaching (3rd ed.). Champaign, IL: Human Kinetics.

Martensen, A., \& Gronholdt, L. (2001). Using employee satisfaction measurement to improve people management: An adaptation of Kano's quality types. Total Quality Management, 12(7), 949-957.

Matzler, K., Fuchs, M., \& Schubert, A. (2004). Employee satisfaction: Does Kano's model apply? Total Quality Management \& Business Excellence, 15(9/10), 1179-1198.

Messner, M. (1992). Power at play. Boston: Beacon Press.

Miles, M., \& Huberman, A. (1994). Qualitative data analysis. Thousand Oaks, CA: Sage.

Mohr-Jackson, I. (1991). Broadening the market orientation: an added focus on internal customers. Human Resource Management, 30(4), 455-467.

Neuman, W.L. (2000). Social research methods: Qualitative and quantitative approaches (4th ed.). Boston: Allyn and Bacon.

Nilsson-Witell, L., \& Fundin, A. (2005). Dynamics of service attributes: A test of Kano's theory of attractive quality. International Journal of Service Industry Management, $16,152-168$.

Ostroff, C. (1992). The relationship between satisfaction, attitudes, and performance: An organizational level analysis. The Journal of Applied Psychology, 77, 963-974.

Pastore, D.L. (1993). Job satisfaction and female college coaches. Physical Educator, 50, 216-221.

Raedeke, T., Warren, A., \& Granzyk, T. (2002). Coaching commitment and turnover: A comparison of current and former coaches. Research Quarterly for Exercise and Sport, $73,72-86$ 
Ronana, W.W., \& Latham, G.P. (1974). The reliability and validity of the critical incident technique: A closer look. Studies in Personnel Psychology, 6(1), 53-64.

Ryan, J. (1995). Little girls in pretty boxes: The making and breaking of elite gymnasts and figure skaters. New York: Doubleday.

Sagas, M., \& Cunningham, G. (2005). Work-family conflict among college assistant coaches. International Journal of Sport Management, 6, 183-197.

Sage, G. (1998). Power and ideology in American sport (2nd ed.). Champaign, IL: Human Kinetics.

Sandelowski, M. (1993). Theory unmasked: The uses and guises of theory in qualitative research. Research in Nursing \& Health, 16, 213-218.

Snyder, C. (1990). The effects of leader behavior and organizational climate on intercollegiate coaches' job satisfaction. Journal of Sport Management, 4, 59-70.

Spector, P. (1997). The role of frustration in anti-social behavior at work. In R.A. Giacalone \& J. Greenberg (Eds.), Anti-social behavior in the workplace (pp. 1-17). Thousand Oaks, CA: Sage.

Staines, G., \& Pleck, J. (1984). Nonstandard work schedules and family life. The Journal of Applied Psychology, 69, 515-523.

Steel, R., \& Rentsch, J. (1997). The Dispositional model of job attitudes revisited: Finding of a 10-year study. The Journal of Applied Psychology, 82, 873-879.

Stitt-Gohdes, W.L., Lambrecht, J.L., \& Redman, D.H. (2000). The critical-incident technique in job behavior research. Journal of Vocational Education Research, 25(1), 63-89.

Strauss, A., \& Corbin, J. (1998). Basics of qualitative research: Techniques and procedures for developing grounded theory ( 2 nd ed.). Thousand Oaks, CA: Sage.

Theberge, N. (1992). Managing domestic work and careers: The experiences of women in coaching. Atlantis: A Women's Studies Journal, 17, 11-21.

Vroom, V.H. (1964). Work and motivation. New York: Wiley.

Weiss, M., \& Stevens, C. (1993). Motivation and attrition of female coaches: An application of social exchange theory. The Sport Psychologist, 7, 244-261.

Woolsey, L.K. (1986). The Critical Incident Technique: An innovative qualitative method of research. Canadian Journal of Counselling, 20(4), 242-254.

Yusof, A. (1998). The relationship between transformational leadership behaviors of athletic directors and coaches' job satisfaction. Physical Educator, 55, 170-176.

Zimbalist, A. (1999). Unpaid professionals: Commercialism and conflict in big-time college sport. Princeton, NJ: Princeton University Press.

\section{Appendix A: Interview Guide}

1. Tell me a little bit about your coaching background:

a) How long have you been a head coach?

b) How many years in this organization?

c) What other coaching positions (assistant, athletic director, etc.)

d) Other noncoaching positions

2. Think of a time when you felt exceptionally good about your present job.

Tell me about that experience.

How long did this good feeling last?

Was what happened typical of what was going on at the time?

How did these feelings affect the way you did your job?

Did what happened affect how you felt about your job, your career, the event itself? (How strongly 1-10)? 
3. Think of a time when you felt exceptionally bad about your present job.

Tell me about that experience.

How long did this bad feeling last?

Was what happened typical of what was going on at the time?

How did these feelings affect the way you did your job?

Did what happened affect how you felt about your job, your career, the event itself? (How strongly 1-10)?

4. Following this line of thinking, what things in general make you feel good about your present job?

5. Following this line of thinking, what things in general make you feel good about your present career?

6. What things in general make you feel frustrated or unhappy about your present job?

7. What things in general make you feel frustrated or unhappy about your present career?

8. When you think about your current job, what elements make you want to stay here?

9. What elements make you want to leave here?

10. What elements make you want to stay in coaching in general?

11. What elements make you want to leave coaching altogether?

12. It seems that there might be a number of frustrating factors about the job of coaching, particularly at D3. In your words, in spite of these frustrations, why do you still coach?

13. Anything else you want to say. 